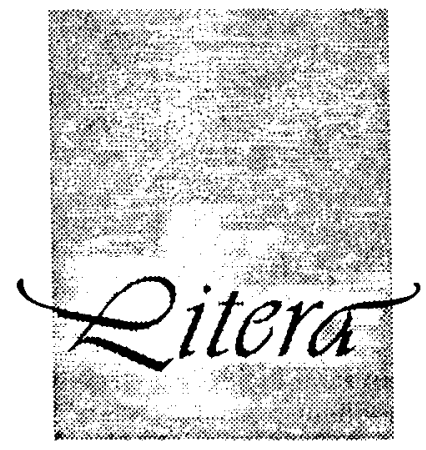

$\begin{array}{llr}\text { Joan Hambidge } & \text { Gedig } & 127 \\ \text { E.Terblanche } & \text { Gedig } & 128 \\ \text { Martie Muller } & \text { Gedig } & 129 \\ \text { Winnie Rust } & \text { Die lig } & 131\end{array}$

Rubriek vir skeppende werk

Met die afdeling Litera tree ons toe tot die mark vir skeppende werk in al die tale waar daar normaalweg in Literator geskryf word.

Dit is die wens van die Redaksie dat die gedigte en kortverhale wat hierby verskyn, baie gedigte, kortverhale en prosa- en dramafragmente in ander inheemse tale sal roep, sodat hierdie blad één geîntegreerde beeld van die korter skryfwerk van jong Suid-Afrikaanse skrywers kan bied.

Dit is met vreugde dat ons die uitnodiging aan veral digters en kortverhaalskrywers rig om skeppende werk voor te lê vir plasing in hierdie rubriek, met die voorbehoud dat ons nie oor die mannekrag beskik om daaroor te korrespondeer nie. Bydraes in viervoud moet in dubbelspasiëring getik wees, met die naam en adres van die insender regs bo aan die eerste blad van gekramde tekste en op elke losbladvel wat gestuur word.

Stuur alle bydraes aan die Hoofredakteur, Literator (629), Buro vir Wetenskaplike Tydskrifte, Privaatsak X6001, Potchefstroom 2520.

\title{
Section for creative writing
}

In introducing the section Litera we are entering the market for creative work in all the languages that Literator normally caters for. It is the wish of the Editorial Board that the poems and short stories printed in this issue will only be the precursor of many poems, short stories, prose and drama fragments in all the indigenous languages, so that the journal will be able to present one integrated image of the short pieces of writing which young South Africans can offer.

It is with great joy that we extend this invitation to especially poets and short fiction writers to submit creative work with a view to publishing them in this section. The only reservation is that we do not have the manpower to enter into correspondence about the works submitted. Four copies of contributions have to be submitted. The submissions have to be typed in double spacing, with the name and address of the author at the top right of the first page of stapled text, and on every loose sheet sent in.

Send all contributions to the Editor-in-Chief, Literator, (629), Bureau for Scholarly Journals, Private Bag X6001, Potchefstroom 2520. 
126 


\section{Vier windstreke}

Uitgestal op die lawn sit die vier susters, wagtend op die sluiter se geluidlose oopmaak.

Kyk, hoe netjies sit hul in 'n kring - met "beste" klere nogals aan -

Al vier onderling saamgesnoer, 'n gebreekte string geërfde krale.

Die een kyk oopoog in die son;

'n vuur van voorgevoel gloei deur die ander.

Die oudste lag swanger oor haar lot;

die jongste wil wegvlug van dié groep se onderhandse oos-wes-tuis-pyn-band.

Uitgestal sit die susters op die lawn, wyl die lewe ondertussen oordeel vel, hul uitstrooi, gebreekte krale wat lig opvang. 


\section{Halfmens}

In verstarde groei

tussen rots en grint,

uitgelewer aan die Suidewind

die hoof fototropies

hunkerend

gerig op die son

net die stilte om haar

staan sy:

Pachypodium Namaquanum

$\mathrm{Na}$ winter-kilte

tussen grys-groen blad

en gekwetste stam

die holle buisblom

- groen van buite

bloeiend-rooi die hart -

die vrug:

'n leë kokon.

Immer alleen

Half-mens 


\section{huisvrou-blues}

\section{I}

deur die reënnat ruit sien ek helder

hoe die reën die kluite blus

en die grond weer spitsag maak

in die reënnat ruit

staan die dwarrelbeeld

van 'n kastrolsiek vrou

deurgeprut en drooggekook

II

vyf vingers

knel die wortel vas

'n vuis

vou die meshef toe

en die wrede riffelkant

stroop die afgeskraapte wortel

van sy vorm

my vuis ontlaai sy hefboomkrag

en gooi die stukkies

lig

in die kastrol 


\section{Saul}

deur die skreefoop venster

het satan vinnig ingeklim

in sy satrape lag het hy

met God gespot:

so sawwerig

met die kussings van sy poot

Saul se dun vel deurgeskaaf

en snare senuwees ontbloot

Saul vat sy spies laag

en smyt sy haat

diep

tot diep die muur in vas 


\section{Die lig}

Ma het vir hom wat Appie is gestuur. "Gan sê vir antie Geraldien-hulle op Wamakersvlei van Clairy se afsterwe", het Ma gesê. Ma se stem was nog dik van die huil.

So ver soos hy gehol het, van Môrelig na Wamakersvlei, het hy nie gedink nie, ook nie die sandpad met die los klippe onder sy kaal voete gevoel nie, hy wou net gou daar kom om vir antie Geraldien en vir Donovan van Clairy te sề, so of die sề die klont in sy keel sal kleiner maak. Die laaste week of wat slaap hy al sonder Clairy se warm lyf agter hom as Ma die kers doodblaas, en dis al of hy geweet het Clairy gaan nie terugkom nie. Oom Kerneels sê sy't die kyk van die dood in haar oë gehad, die lag was weg. Laasnag was hy bang vir die donker, hy't gewonder waantoe Clairy is. Daar's 'n ander donker plek ook waarvan oom Solly Sondae preek. Toe wou hy by Ma gaan lê, maar Siena en Setta lê vas teen Ma van Pa dood is.

Toe hy die perdeskoen se draai vat, sien hy die enerse swart dakke van Wamakersvlei se nuwe huise uitsteek, en langes die tweede een, antie Geraldien s'n, sien hy van ver af ook die rooi van David se Ford Escourt wat langes die huis staan.

Hy hol die laaste ent nog vinniger, en toe hy na aan die huise kom, hoor hy skaars die kleingoed se "Appi-e-e!!! Appi-e-e!!!" Hy hol tot teen die rooi Escourt aan. Donovan sit agter die wiel. Donovan sien hom nie eers nie, hy luister na Radio Five.

"Clairy het afgesterwe," skree hy hard, teen die toe ruit aan.

Toe eers stamp Donovan die mouterdeur met sy skouer oop, en hy klim uit, maar ook nie vinnig nie, of hy nie reg gehoor het nie.

"Wat gaap jy met jou bek oop en toe soos 'n vis?" vra Donovan.

"Clairy het afgesterwe," sê hy weer, dié keer sagter, en hy voel hoe sy stem dun raak.

"Wragtag," sê Donovan toe, na 'n tyd. "Bliksem, né."

"Ma!" skree hy na die voordeur se kant toe. "Ma!!!"

Toe sy in die voordeur kom staan, het antie Geraldien twee rooi kolle op haar geel wange. Dit slaan so uit as sy kwaad word. David is geel, soos sy ma. Donovan is donker, soos sy pa.

"Watse geskree is dit met jou Donovan?"

Antie Geraldien kan kookwater wees. Haar stem sny soos die winterwind deur jou hemp. Antie Geraldien moet die pot aan die kook hou, sê Ma. Oom Gert suip die laaste sent uit. Toe sê Donovan vir antie Geraldien van Clairy se afsterwe. "Here kind," sê antie Geraldien, "kom hier." 
Toe hy nader loop, kom David van agter, van die kombuis se kant af, en kom in die deur staan. Hy 't so skeef teen die deur aangeleun, hardegat soos altyd, met sy spanbroek en sy leerjacket, sy jelly-hare en sy patent-skoene, en niks gesê nie, net vir hom wat Appie is, gekyk. Hy kon skaars by die voordeur inkom, so vol het David die deur gestaan. Binne het hy die sement van die nuwe huise geruik, anders as die ruik van die rook en die vuur in Môrelig se huise.

"Praat kind," sê antie Geraldien toe, en pluk aan sy skouer. Toe praat hy vinnig en deurmekaar.

"Clairy is innie hospitaal dood ... vannie longe ennie swak hart ... Ma het allie clinic se pille opgebruik met die laaste toe bors van Clairy ... dit hettie gehelp nie, toe's sy hospitaal toe, toe't hulle net vir Kleinbaas lat wiet sy't afgesterwe ..."

Hy wou nog sề van oom Kerneels en oom Jan en Boeta Bul wat die gat onder die rivier langes $\mathrm{Pa}$ aan die grawe was, maar dit was of hy nie meer lekker kon dink nie van dieselle ding te moet oorsê. Toe't hy gekyk na die blink goed om hom, die elektriek ketel en die stoof en die strykyster wat inplug, en die tiewie. Al die dinge het saam met die lig vir Wamakersvlei se mense gekom. Hy't gedink aan wat David gesê het, die vorige keer toe hy op Wamakersvlei was: "Julle in julle dônnerse krotte, julle moet julle koppe laat lees, julle is met alles tevrede."

Toe stuur antie Geraldien vir Donovan na oom Gert toe. Hy moes weer terug huis toe. Ma het gesê sy trek sy stertvel af as hy weer met Donovan en sy bike deurmekaar raak, hy moet nog loep hout haal.

"Donovan, loep sề vir jou pa-hulle in die skuur van Clairy," het antie Geraldien gesê. "En maak gou, los nou die verdomde mouterkar uit."

Al die mans kyk op 'n Saterdagmiddag football, dié wat nie dikgesuip is nie.

Toe hy weer loop, moes hy teen David verby skuur wat nog breed in die deur staan, met sy hand in sy sy.

"So Clairy het 'afgesterwe', sê jy. En wie se skuld is dit, dink jy? Julle op Môrelig is ammal blêrrie poppe van die wittes wat julle laat vrek in koue nat huise."

Hy kon David ruik, so naby het David teen hom gekom. David ruik na die skerp goed uit die spuitkan van die chemist.

"David," sê Donovan toe, "vat vir Appie vir 'n spin huis toe."

"Die kar is opgeneuk met die laaste rots, die gearbox is in sy moer." David se stem is hoog en hard. Dit was dié keer toe sy radio cassette met die twee speakers uit sy kamer gevat is, dié dag toe hy saam gemarch het. Dit was eers peaceful protest maar 'n klomp mouters en winkelvensters is stukkend gegooi toe die spul begint wild raak, en die mense by Wes-Kaap se kamers is almal geraid.

Dit was met die terughol dat hy, Appie, gedink het. Twee maande gelede, toe begint kap hulle aan die huise op Môrelig ook, vir die pype vir die elektriek drade, oom Kerneels en 
oom Jan en Boeta Bul. Alles is nou reg, die drade en die switches, dis nou nog net die elektriek wat moet aan. Oom Kerneels sê dis die Stigting wat maak dat môrelig ook gaan lig kry. Daai dag was David weer daar, toe sê hy: "Dis verdomp hoog tyd, julle base mors met julle, julle is suckers. Dis oor julle nie unions het nie dat julle alles doen wat die base sê."

By die gat in die draad wat Môrelig van Wamakersvlei skei, onthou hy hoe hy en Clairy deurgekruip het om die eerste vroe-koejawels van baas Ferdinand by te kom. Hulle't hande vol gepluk en in sakke gesteek en saans in die donker lê en kou, lank na oom Kerneels verby geloop het, dik geëet aan Ma se viskos. Ma het nog in die half-donkerte met die vuil blikborde voor die stoof gevroetel, en Abe en Moos in die een hoek en Ragel en Lena op die grondbed was lankal vas aan die slaap. Clairy se gehoes kon hulle nie eers wakker kry nie.

"Clairy, hoe sillit wies om lig te hê, soos Donovan-hulle?" Dis net oor Ma kan skel dat hy sag praat.

Clairy het gekou en gehoes, gekou en gehoes, en van hom weggeskuif.

"Sies Appie, jy stink. Het jy gewas? As jy grand wil wies soos Donovan-hulle, moet jy vir jou was."

Hy't sy vuil voete onder die kombers ingetrek, of Clairy kon sien in die donkerte, en net gesê:

"Dit lieg jy Clairy," maar hy't geweet hy's lui vir was by die kraan, so sonder Clairy, oor haar bors te toe was vir buitekant was. Hy sal Kaap toe gaan, eendag, en 'n mouter koop en ruike van hom afgooi soos koejawelskille.

Toe vat hy die draai onder langes die rivier, en toe sien hy vir oom Kerneels en vir Jan en vir Boeta Bul in hulle blou overalls, besig om annerkant teen die skuinste Clairy se gat te grawe. Hy sien hoe hulle blou overalls wegraak en opkom, wegraak en opkom soos hulle grawe en gooi, grawe en gooi, en toe voel hy sy wange word nat. Toe weet hy nie lekker of dit van die koue wind op sy wange en in sy neus is nie, en of dit oor Clairy is nie.

Toe die bokant van die gewel van die plaashuis bo die koejawelboord begint uitsteek, sien hy die wit bakkie wat hy nie ken nie met die leer bo-op vas voor die plaashuis staan. Dis nes iets vir hom sê dis nou die elektriesjin met die lig. Oom Kerneels het gesê van die elektriesjin wat van die dorp kom met die lig. Hy't op sy laaste asem nog vinniger gehol, die laaste skuinstetjie voor die huise uit tot waar Ma in die voordeur hande in die sy staan en wag.

"Vir wat speel jy so dat jy byna sononder hier aankom as ek sê jy moet gou maak? Abe en Moos is al weg vir die hout." Ma wou hom sommer pluk, maar Siena en Setta was in die pad. Hulle't skreërig aan Ma se pante vasgehou.

"Wat sê antie Geraldien-hulle?"

Hy't op die stomp voor die deur gaan sit, en eers nie gepraat nie. Vir wat pluk Ma alewig aan hom? Hy moet wegkom uit die krotte, sê David. Wegkom en Kaap toe gaan en geld 
maak.

"Antie Geraldien-hulle kom, antie Geraldien sê ek moet vir Ma sê hulle is jammer oor Clairy."

Toe was dit of ma weer van voor af wil huil, na al die gehuil van die vorige dag, en Ma vee met haar rokpante oor haar oë.

Ma het in die donker huis ingegaan en die as uit die houtstoof gekrap, en gevra of David daar was. Toe't hy vertel van David, en van hulle wat suckers is. Toe't Ma uit haar huilstem uit begint te skel, en gesê David kan maklik praat, hy met sy Kaapse maniere wat vir hulle wil kom voorsê, hy's nooit daar as antie Geraldien hulle nodig het nie, hy koop grand mouters met die company se geld maar bring niks in nie, antie Geraldien kry swaar met Gert se gesuipery.

Toe sê hy maar van die bakkie met die leer voor die plaashuis, dat Ma kan ophou skel. Toe sê Ma sien is glo, sy glo niks voor sy nie sien nie, hulle bly aan die uitstel met die lig.

"Ma," vra hy toe, "hoe kom Clairy hier?"

"Baas Ferdinand sal met die bakkie by die lykhuis vir Clairy gaan haal. Oom Kerneels sal 'n plankkis aanmekaar timmer."

Daar's nooit geld nie, daar's nooit geld vir niks nie, ook nie vir 'n kis vir Clairy nie, dink hy.

Toe begin Ma weer van vooraf huil en Siena en Setta skree agterna, en hy sit net daar en dink aan al hierdie dinge, en oor hoe 'n mens daarvan kan wegkom.

Nou staan hulle hier langs Clairy se graf, in die sifreën, dis nou Môrelig se mense en antie Geraldien-hulle van Wamakersvlei, behalwe David. David is terug Kaap toe. David sê hy kom nie na 'n sendingkerk se begrafnis nie, dis soos die wittes se kerk, maar miskien is dit omdat baas Ferdinand hom eendag van sy plaas afgejaag het - "Jou blêrrie Kaapse hotnot wat soek jy op my werf, jy kom net onrus stook." Van daardie dag af is David meer bitterbek, en sit hy nie sy voete op Môrelig nie.

Van die diens in die saal op die plaas onthou hy min, die banke is hard en dis koud en oom Solly preek lank.

"Sustertjie Clairy is ons vroeg ontneem," sê oom Solly. "Haar liggie het hier op aarde uitgegaan maar skyn op 'n beter plek." Dit verstaan hy nie, hy't gedink aan Clairy wat in die plankkis by die uitgang van die saal lê, toegepak onder die laat asters van die plaas, en wat nou hier in die gat afsak, na oom Kerneels en Jan en Boeta Bul haar hiernatoe gedra het. 
Nou staan hulle maar hier, teenmekaar vasgehok soos nat hoenders onder die paar sambrele, terwyl Clairy se blomkissie stadig afsak en oom Kerneels se koor sing, lankuitgerek met antie Sarah se hoë stem vooraan. "Lei Vriend'lik lig, deur aardse duisternis lei U my voort." Clairy het dit altyd gesing. Hier staan hy nou maar met sy bek vol tande en probeer die huil wat swaar in sy keel kom lê het, afsluk. Ma en antie Geraldien huil verskriklik, dit ruk uit hulle lywe, of hulle wil braak, soos die keer toe Clairy te veel vroekoejawels geëet het. Moos, Siena en Setta huil almal saam, Siena en Setta baie hard, soos altyd. Donovan staan heel agter en kyk anderpad. Toe gooi hy maar die heel laaste blom op die kis, voor oom Kerneels en Jan en Boeta Bul netnou begin toegooi. Oom Sollie sê van die koek en die ietsie te drinke in die skuur, en van meneer Ferdinand en miss Martie Malan se goedgeit, maar toe loop hy sommer huis toe, weg van alles af.

Toe hy by die huis kom, was dit of iets voor hom sê om aan die lig se switch te vat, soos wat hy elke dag maak as hy van die skool af kom, toe wil hy sommer huil van al die inhou by die begrafnis ook, want daar's dit toe, die lig is aan en elke stukkie meubel kan hy sien, al was dit sesuur in die aand en donker winter. Maar dis of die donker dit beter toegemaak het, die muurpapier wat Clairy en hy geplak het wat van die nat afdop, die matrasse op die vloer met die springs wat uitsteek langs die grys Pep Stores-komberse, en die vuil swart houtstoof waarop Ma se bredies altyd kook. Dis toe of hy al hierdie dinge vir die eerste keer behoorlik sien. Hy't lank so gestaan, en net gekyk.

Later, baie later, toe Ma-hulle daar aankom sê hy: "Ma, Ma die lig is aan," toe sê Ma "Appie as jy vir my lieg ..." toe sê hy "maar kan Ma dan nie sien dis lig nie" toe sê Ma "ja wragtag ek sien nou, ek is skoon simpel gehuil oor Clairy dat ek dit nie sien nie," toe slaan Ma die switch aan en af, aan en af, dan's dit lig, dan's dit donker, net om seker te maak dis rêrig so, die lig is aan. Toe kom Abe en Moos, Ragel en Lena, Siena en Setta almal en hulle vat aan die switch, aan en af, aan en af, tot Ma sê "hou nou verdomp op, moenie maak of julle niks gewoond is nie." Toe eers dink hy aan die ketel en die stoof en die lig vir saans lees, en die tiewie.

Toe kom Donovan daaraan, wit geskrik, hy sê David is in die Kaap met 'n baksteen deur die Ford Escourt se ruit gegooi, hy bloei en is in die hospitaal, langes die pad by Wes-Kaap gooi hulle klip, ses mouterryers het al seergekry, al die straatlampe is uit, dis donker langs die pad.

Hy't na Donovan se wit gesig gekyk. Hy't gedink aan al die elektriek goed in Donovanhulle se huis.

Siena en Setta begint weer skree.

Hy kyk in die kamer rond, na al die ou bekende dinge wat nou lig op het, of hy dit vir die eerste keer sien. Alles lyk anders in die helder wit lig.

Toe't hy onthou. Hy't onthou van die kere toe hy warm agter Clairy se blad gelê het en Ma se kos geruik het en die kers al lig was. 